\title{
Correction to: Genetic aberrations of the K-ras proto-oncogene in bladder cancer in relation to pesticide exposure
}

\author{
Diaa A. Hameed ${ }^{1} \cdot$ Heba A. Yassa ${ }^{2}$ (D) $\cdot$ Michael N. Agban ${ }^{3} \cdot$ Randa T. Hanna $^{4} \cdot$ Ahmed M. Elderwy $^{1} \cdot$ Mohamed A. Zwaita $^{1}$
}

Published online: 3 July 2018

(C) Springer-Verlag GmbH Germany, part of Springer Nature 2018

\section{Correction to: Environ Sci Pollut Res \\ https://doi.org/10.1007/s11356-018-1840-6}

The original publication of this paper contains a mistake.

Line 6 in the abstract, line should read "One hundred patients were diagnosed with bladder cancer and two hundred controls attended the outpatient clinic;"

2nd paragraph of the Methods section, the correct line should read "This study included 100 cases newly diagnosed with histopathologically proven bladder cancer and 200 controls who attended the outpatient clinic."

The original article has been corrected.

The online version of the original article can be found at https://doi.org/ 10.1007/s11356-018-1840-6

Heba A. Yassa

hebayassa@aun.edu

1 Urology Department, Assiut University, Assiut, Egypt

2 Forensic Medicine and Clinical Toxicology Department, Assiut University, Assiut, Egypt

3 Microbiology Department, Assiut University, Assiut, Egypt

4 Biochemistry Department, Assiut University, Assiut, Egypt 